\title{
Role of low circulating FSH concentrations in controlling the interval to emergence of the subsequent follicular wave in cattle
}

\author{
O. J. Ginther ${ }^{1,2}$, D. R. Bergfelt ${ }^{1}$, M. A. Beg${ }^{1}$ and K. Kot ${ }^{1,2}$ \\ ${ }^{1}$ Department of Animal Health and Biomedical Sciences, 1656 Linden Drive, \\ University of Wisconsin, Madison, WI 53706, USA; and ${ }^{2}$ Eutheria Foundation, \\ Cross Plains, WI 53528, USA
}

The intervals between emergence of follicular waves 1 (first wave of an oestrous cycle) and 2, and between the associated FSH surges (surges 1 and 2), were studied in control $(n=7)$ and recombinant bovine $(r b) F S H-t r e a t e d$ $(n=7)$ heifers. The expected start of the deviation in follicle diameter between the two largest follicles of wave 1 was defined as the day on which the largest follicle reached $8.5 \mathrm{~mm}$ (day 0 ). In the control heifers, circulating concentrations of FSH decreased and oestradiol increased between day 0 and day 1.5 or day 2.0 in a reciprocal relationship. The opposite reciprocal relationship between an FSH increase and an oestradiol decrease occurred during the next 3 days. This temporal result is consistent with a negative systemic effect of oestradiol on FSH at this

\section{Introduction}

Two or three follicular waves develop during the bovine oestrous cycle (Ginther et al., 1989). Each wave is preceded by a surge in circulating FSH (Adams et al., 1992). The FSH surge and the resulting follicular wave that develop at the start of the oestrous cycle are termed surge 1 and wave 1 , and are followed in about 10 days by surge 2 and wave 2 . When the largest follicle of a wave reaches a mean diameter of $8.5 \mathrm{~mm}$, the follicles begin to deviate in diameter into a single dominant follicle and several subordinate follicles (Ginther et al., 2001a). The FSH concentrations continue to decrease for approximately 1 day after the start of deviation in follicle diameter. Surge 2 stimulates the emergence of follicles $4 \mathrm{~mm}$ in diameter from wave 2 about 10 days after emergence of wave 1 or 7 days after the start of deviation in follicle diameter of wave 1 . The changes in the concentrations of FSH and other hormones during the interval between surges 1 and 2 have not been described adequately. Previous studies used reference points near the beginning of wave 1 (Badinga et al., 1992; Sunderland et al., 1996; Evans et al., 1997) or normalized each wave and associated hormone concentrations to follicle emergence (Adams et al., 1992) or deviation (Kulick et al., 2001), thereby obscuring the mean pattern of the circulating hormone concentrations during the transition between surges.

Email: ojg@ahabs.wisc.edu time. rbFSH was administered in a dosage regimen that was expected to result in a similarity between FSH surge 2 in the rbFSH-treated group and surge 2 in the control group. On average, surge 2 and wave 2 occurred approximately 2 days earlier in the rbFSH-treated group than in the control group, and characteristics of the FSH surge and follicular wave were similar (no significant differences) between groups. These results support the hypothesis that low circulating FSH concentrations after the deviation in follicle diameter control the interval to emergence of the subsequent follicular wave. However, in one of seven rbFSH-treated heifers, the largest follicle from the apparent stimulation of rbFSH reached only $5.7 \mathrm{~mm}$; therefore, the possibility of involvement of additional mechanisms cannot be dismissed.

The decrease in $\mathrm{FSH}$ concentrations after deviation in follicle diameter in surge 1 and maintenance of FSH at low concentrations after follicle deviation apparently assure continued FSH deprivation of the subordinate follicles (Ginther et al., 2001a). In addition, the low FSH concentrations may delay the emergence of the next follicular wave until surge 2 develops appropriate FSH concentrations. The depression of circulating FSH during this time has been attributed to the secretion of oestradiol and inhibin by the dominant follicle of wave 1 (for a review, see Ginther et al., 2001a). The dominant follicle may also secrete factors other than oestradiol and inhibin that suppress other follicles either directly (Armstrong and Webb, 1997) or through reduced circulating FSH. In this regard, a steroiddepleted fraction of follicular fluid suppressed follicle development in cattle even though the injected follicular fluid was $>95 \%$ free of inhibin (Law et al., 1992) and suppressed both FSH and follicles despite the injection of an inhibin antiserum with the follicular fluid (Wood et al., 1993). Administration of FSH during the transition between surges 1 and 2 can be expected to shorten the interval between waves 1 and 2, if low FSH concentrations account for the duration of the interval in control heifers. In one study, an FSH-rich pituitary extract administered 5 days after ovulation shortened the interval from treatment to the emergence of wave 2 (Bodensteiner et al., 1996). However, the interpretation was obscured by the ovulation of the dominant follicle of wave 1 in most heifers. In another 
study, recombinant bovine FSH (rbFSH) was administered at days 5 and 6 after ovulation (Adams et al., 1993), which is equivalent to days 2 and 3 after expected deviation in follicle diameter for wave 1. The day of emergence of wave 2 was not hastened by rbFSH treatment, indicating that the low FSH concentrations between waves did not account adequately for the duration of the interwave interval. The results of these studies indicate a need for further study of the mechanism that mediates the hiatus between the emergence of successive waves.

The aim of the present study was to test the hypothesis that low circulating FSH concentrations after deviation in follicle diameter control the interval to emergence of the subsequent follicular wave. The hypothesis was tested by administration of $\mathrm{FSH}$ in a dosage regimen that would produce an FSH surge similar to an endogenous FSH surge. Early emergence of wave 2 was taken as an indication that the hiatus between waves was attributable to the low FSH concentrations, without providing support for the existence of a direct follicle suppressor. In addition, the concentrations of $\mathrm{FSH}, \mathrm{LH}$ and oestradiol during the interval between FSH surges 1 and 2 were characterized.

\section{Materials and Methods}

\section{Animals and ultrasonography}

The experiment encompassed an interovulatory interval. Holstein heifers aged between 24 and 36 months and weighing 490-680 kg were used. The feeding programme, the $\mathrm{PGF}_{2 \alpha}$ (Lutalyse; Pharmacia Co., Kalamazo, MI) protocol for inducing luteolysis to schedule ovulation and the equipment and techniques for transrectal ultrasonography of ovaries and measurement of the follicles were as described by Ginther et al. (2000b). Scanning of follicles was carried out at $24 \mathrm{~h}$ intervals starting on the day of induced luteolysis at mid-dioestrus and continuing until the largest follicle (F1) of wave 1 reached $7.0 \mathrm{~mm}$ in diameter. Thereafter, scanning was carried out every 0.5 days until the largest follicle reached $12.0 \mathrm{~mm}$ in diameter and then every day until ovulation. All follicles that reached $4.0 \mathrm{~mm}$ in diameter were tracked from examination to examination until they regressed to $<4.0 \mathrm{~mm}$ in diameter as described by Ginther et al. (1989).

\section{Collection of blood samples}

Blood samples were collected by jugular venepuncture every day from the time at which the largest follicle was 4-7 $\mathrm{mm}$ in diameter and then every 0.5 days until ovulation. The samples were centrifuged at $500 \mathrm{~g}$ for $10 \mathrm{~min}$ and the plasma was decanted and stored at $-20^{\circ} \mathrm{C}$ until assayed for FSH, LH and oestradiol.

\section{Definitions}

Follicle emergence was based on the day a follicle was first detected to be $\geqslant 4.0 \mathrm{~mm}$ in diameter. The day of wave emergence was determined retrospectively as indicated by either the emergence of the first follicle of the wave, emergence of the future dominant follicle or emergence of the future largest subordinate follicle. The number of days involved in emergence ( $\geqslant 4.0 \mathrm{~mm}$ in diameter) of all follicles of the wave (base of wave) was determined by consecutive days with an emerging follicle, after allowing for 0.5 days without an emerging follicle. All follicles that were $\geqslant 4.0 \mathrm{~mm}$ in diameter were used to define the base of the waves. The number of follicles per wave was categorized as follicles with a diameter of $\leqslant 4.9 \mathrm{~mm}$ and $\geqslant 5.0 \mathrm{~mm}$. The follicular waves were defined as major when $\mathrm{F} 1$ reached $\geqslant 10.0 \mathrm{~mm}$ in diameter and as minor when the $\mathrm{F} 1$ reached $<10.0 \mathrm{~mm}$ in diameter. Two follicles that reached $\geqslant 10.0 \mathrm{~mm}$ in diameter identified a wave with double dominant follicles. For such waves, F3 was used or the largest subordinate follicle, whereas F2 was used for waves with a single dominant follicle. The day on which F1 of wave 1 reached a mean of $8.5 \mathrm{~mm}$ in diameter was designated day 0 (expected start of deviation). As a result of the 0.5 day interval between scanning sessions, day 0 was determined as the day on which F1 first reached $\geqslant 8.2 \mathrm{~mm}$ in diameter to obtain a range of actual diameters with an average of approximately $8.5 \mathrm{~mm}$ (Ginther et al., 2001a).

\section{Treatment groups and endpoints}

The heifers were selected at random into control (saline vehicle, $n=7$ ) and rbFSH-treated ( $n=7)$ groups. Heifers in the rbFSH group were given i.m. injections of recombinant DNA-derived bovine FSH (Granada Biosciences, Marquez, TX) reconstituted with physiological saline. The control heifers were given a volume of saline vehicle corresponding to the volume required for delivery of rbFSH. The treatments began on day 3 or 3 days after the beginning of the expected deviation in follicle diameter in follicular wave 1 . The following dosage schedule for rbFSH was used: (i) day 3.0, $1.0 \mathrm{mg}$; (ii) day 3.5, $2.0 \mathrm{mg}$; (iii) day 4.0, $3.5 \mathrm{mg}$; (iv) day 4.5, $2.0 \mathrm{mg}$; and ( $\mathrm{v}$ ) day 5.0, $1.0 \mathrm{mg}$. rbFSH was used to permit evaluation of the effects of homologous FSH on the emergence of wave 2.

$\mathrm{FSH}, \mathrm{LH}$ and oestradiol concentrations for day -1 to day 6 in the control heifers were used to characterize the temporal hormonal relationships for the intersurge interval and including the last portion of surge 1 and the first portion of surge 2. The days used were intended to represent the interval from the expected start of deviation in follicle diameter in wave 1 to emergence of wave 2. The data for the diameters of F1 and F2 and for FSH concentrations extending from the pretreatment ovulation to treatment after ovulation were used to compare groups by normalizing to the beginning of each major and minor wave, as determined from emergence of F1. The diameters of the F1 and $\mathrm{F} 2$, and $\mathrm{FSH}$ concentrations were compared between groups by normalizing the three endpoints to the day of emergence of the dominant follicle of wave 2 . The induced 
FSH surge 2 in the rbFSH-treated group and surge 2 in the controls were normalized to the first apparent increase in the FSH means, and the two surges were compared for the following 5.5 days. An interval of 5.5 days was used because the mean FSH concentrations had returned to mean values that were equivalent to the onset of the surges in both groups. Discrete endpoints for comparing surge 2 and wave 2 between the control and rbFSH-treated groups were characteristics of the FSH surge (peak or maximal concentration, interval from day 3 to peak), day of emergence of follicles, maximum diameter of dominant follicle, and characteristics of the follicular wave (width of base, numbers of follicles).

\section{Hormone assays}

Plasma concentrations of FSH and $\mathrm{LH}$ were determined using radioimmunoassay; details on the modifications and validations for use in this laboratory for FSH (Adams et al., 1992) and LH (Ginther et al., 2000b) have been reported. The crossreactivity of the rbFSH preparation with reference to the bFSH standard (AFP-5318C) used in the assay was $<1 \%$. Mean assay sensitivity was $0.01 \mathrm{ng} \mathrm{ml}^{-1}$ for $\mathrm{FSH}$ and $0.2 \mathrm{ng} \mathrm{ml}^{-1}$ for $\mathrm{LH}$. The intra-assay coefficients of variation were $4.1 \%$ for $\mathrm{FSH}$ and $5.4 \%$ for $\mathrm{LH}$.

Oestradiol was measured in plasma samples using a commercially available radioimmunoassay kit (Ultra Sensitive Estradiol assay, DSL-4800; Diagnostic Systems Laboratory, Webster TX) that has been validated for analysis of bovine samples (Turzillo and Fortune, 1990). Assay details as used in this laboratory are described by Kulick et al. (1999). Mean assay sensitivity was $0.35 \mathrm{pg} \mathrm{ml}^{-1}$. The mean intra- and interassay coefficients of variations were $6.8 \%$ and $7.3 \%$, respectively.

\section{Statistical analyses}

The sequential follicle and hormone data were normally distributed, and data transformation was not used. Sequential data were analysed by MIXED procedures with a repeated statement and a first order autoregressive structure to account for autocorrelation between sequential measurements. The analyses considered the circulating hormone concentrations and diameters of F1 and F2 in the control heifers on days -1 to 6 , differences in $\mathrm{FSH}$ concentrations between control and rbFSH-treated groups on days 0-10, comparison of surge 2 between the two groups with the data normalized to the day preceding the first apparent increase in concentrations, and comparison of diameters of F1 and F2 of wave 2 between the two groups by normalizing to the day of emergence of F1. Significant main effects and interactions were examined further by paired and unpaired $t$ tests. Discrete endpoints were compared between groups by unpaired $t$ tests. The data are presented as the mean \pm SEM. A probability of $P<0.05$ indicated that a difference was significant and probabilities between $P>0.05$ and $P<0.1$ indicated that a difference approached significance.

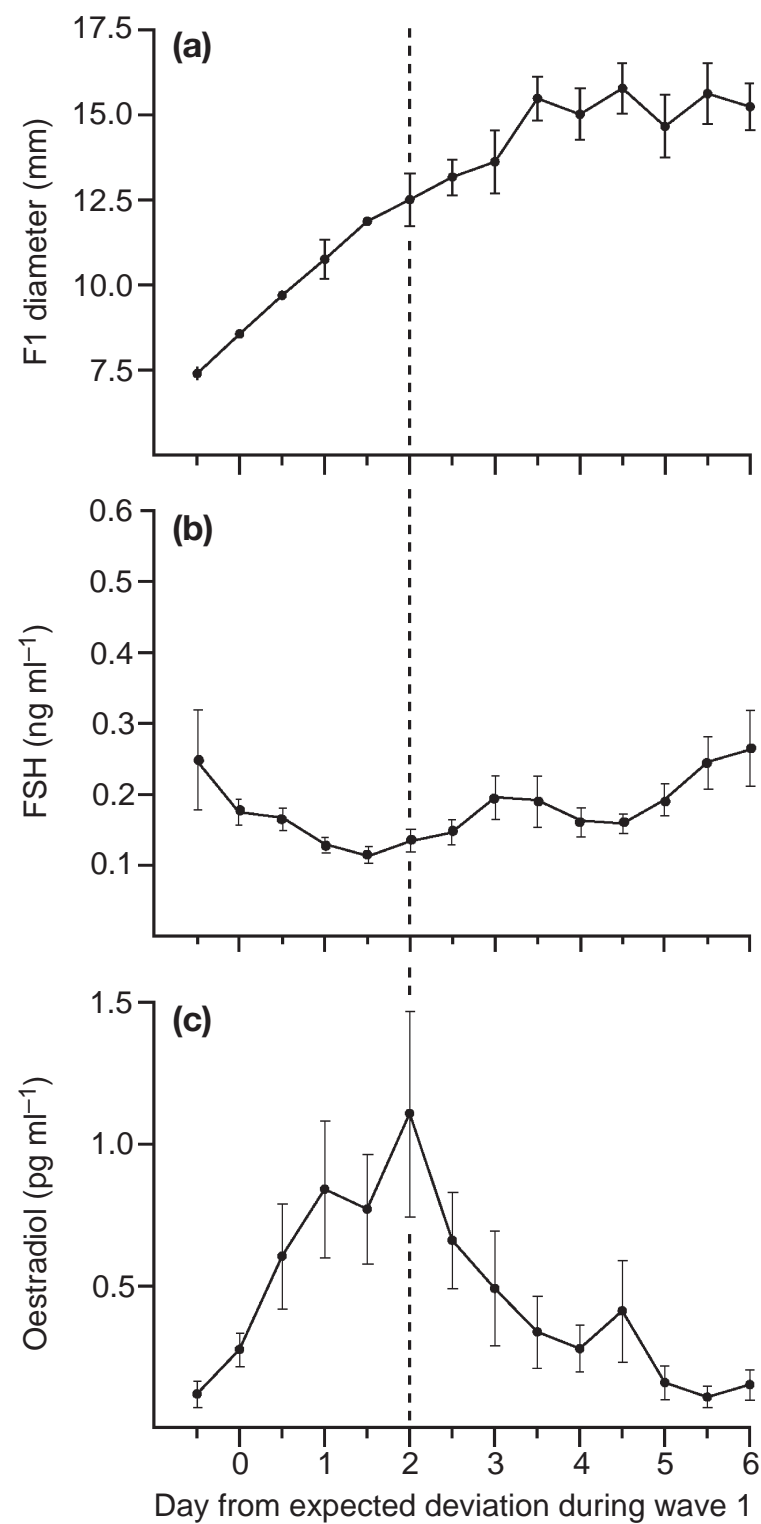

Fig. 1. Means \pm SEM for (a) diameters of the dominant follicle (F1) of wave 1 and circulating concentrations of (b) FSH and (c) oestradiol in the control group $(n=7)$, extending from the later portion of FSH surge 1 to the early portion of surge 2 . Significant effects of day were found for F1 $(P<0.0001), \mathrm{FSH}(P<0.0005)$ and oestradiol $(P<0.0003)$. The vertical broken line shows the maximal oestradiol concentration.

\section{Results}

Mean diameters of the largest follicle, and circulating concentrations of $\mathrm{FSH}$ and oestradiol for day -0.5 to day 6.0 (day $0=$ beginning of expected deviation) in the control group and the results of the statistical analyses are shown (Fig. 1). Concentrations of FSH decreased $(P<0.01)$ between day 0 and day 1.5 , increased $(P<0.01)$ between day 1.5 and day 3.0, decreased (approached significance, $P<0.09$ ) between day 3.0 and day 4.5 , and then increased again $(P<0.01)$. Concentrations of oestradiol increased 


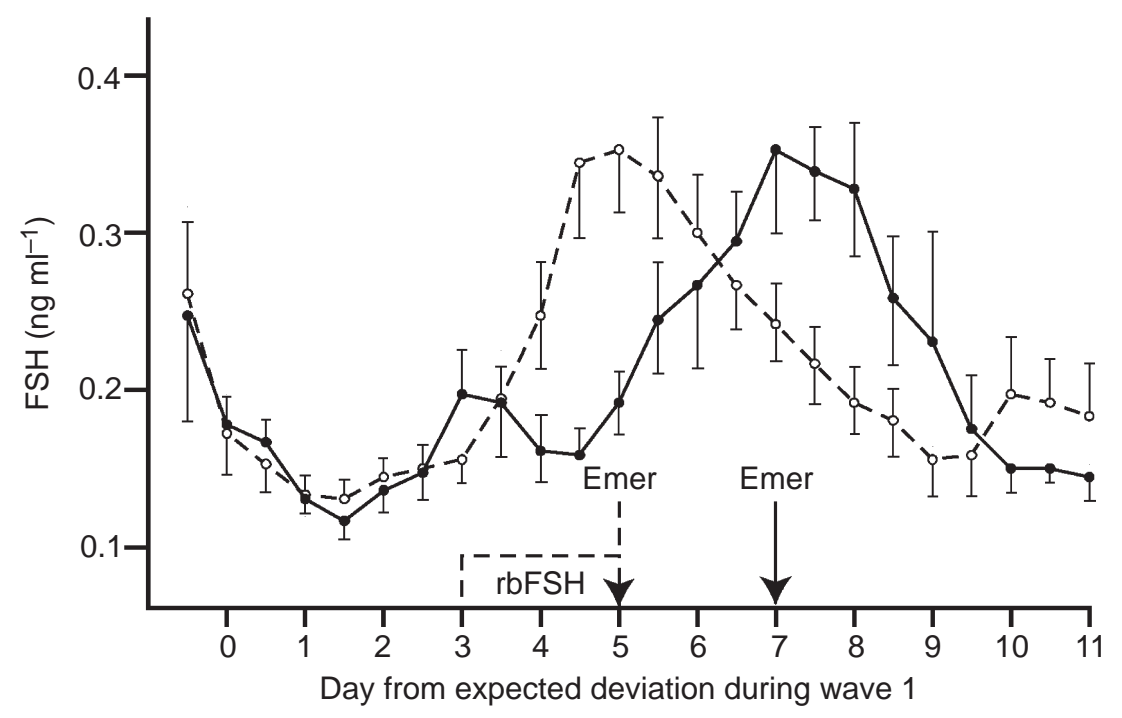

Fig. 2. Means $\pm \operatorname{SEM}(n=7)$ for circulating FSH concentrations of surge 2 in control (O) and recominant bovine (rb)FSH-treated $(\bigcirc)$ heifers $(n=7$ per group). Days of $\mathrm{rbFSH}$ treatment and mean day of emergence (Emer) of the dominant follicle of wave 2 for each group are indicated.

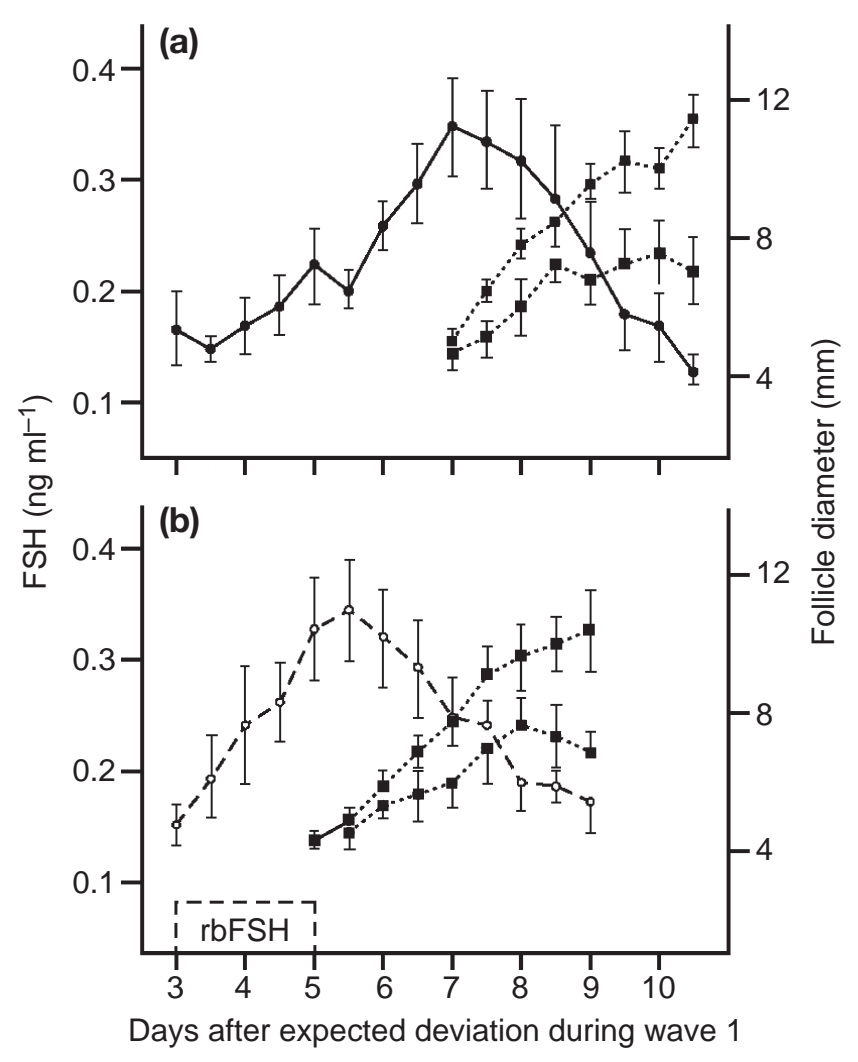

Fig. 3. Means $\pm \operatorname{SEM}(n=7)$ for circulating FSH concentrations of surge 2 in (a) control (- - ) and (b) recombinant bovine (rb)FSHtreated (--O--) groups ( $n=7$ per group) and diameters of the two largest follicles (F1, F2) of wave $2(\cdot \cdot \boldsymbol{\square} \cdot$.$) . Data for all endpoints$ are normalized to the mean day of emergence of the future dominant follicle for each group. Days of rbFSH treatment are shown.
$(P<0.02)$ between day -0.5 and day 2.0 and then decreased $(P<0.02)$. Concentrations of $\mathrm{LH}$ did not change significantly between day -0.5 and day 6.0 (not shown).

The number of major follicular waves per interovulatory interval was two or three in the control heifers and two to four in rbFSH-treated heifers, but the mean number did not differ between the control group $(2.6 \pm 0.2)$ and the rbFSHtreated group $(3.0 \pm 0.3)$. Each major wave of the interovulatory interval was associated with a distinct FSH surge (not shown). A minor follicular wave occurred in seven of the 14 heifers (no difference between groups). The minor waves emerged on average 5.7 days before the ovulation at the end of the interovulatory interval. The maximum diameter of F1 was 5.0-8.7 $\mathrm{mm}$. The follicles started to regress before ovulation.

Surge 2 reached a peak (Fig. $2 ; P<0.0001$ ) and wave 2 emerged (Fig. 3; $P<0.0004$ ) about 2 days earlier in the rbFSH-treated group than in the control group (Table 1). For surge 2, there were significant $(P<0.0001)$ differences among the average number of days for the rbFSH-treated group and the control group for 5.5 days after the first apparent mean $\mathrm{FSH}$ increase; the difference between the two groups and the interaction were not significant (Fig. 2). The mean FSH concentration at the peak of the surge was not different between groups (Table 1). The characteristics of wave 2 were not different between groups, except that the base of the wave was wider in the rbFSH-treated group (Table 1). The temporal relationships between emergence of wave 2 and the peak of surge 2 and the growth profiles for F1 and F2 were not different between groups (Fig. 3). The number of dominant follicles per wave was similar for the control $(1.3 \pm 0.2)$ and rbFSH-treated heifers $(1.4 \pm 0.2)$. There were no differences between groups in maximum 
Table 1. Characteristics (mean \pm SEM) of FSH for surge 2 and follicle endpoints for wave 2 in control and recombinant bovine (rb)FSH-treated heifers ${ }^{\mathrm{a}}$

\begin{tabular}{|c|c|c|c|}
\hline Endpoint & $\begin{array}{l}\text { Controls } \\
(n=7)\end{array}$ & $\begin{array}{l}\text { rbFSH-treated } \\
\quad(n=7)\end{array}$ & Group effect \\
\hline \multicolumn{4}{|l|}{ FSH surge } \\
\hline Peak FSH concentration $\left(\mathrm{ng} \mathrm{ml}^{-1}\right)$ & $0.40 \pm 0.05$ & $0.38 \pm 0.04$ & NS \\
\hline Interval day 3 to peak (days) & $7.4 \pm 0.2$ & $5.1 \pm 0.1$ & $P<0.001$ \\
\hline \multicolumn{4}{|l|}{ Day of emergence } \\
\hline First follicle of wave & $6.8 \pm 0.4$ & $4.7 \pm 0.1$ & $P<0.0001$ \\
\hline Future dominant follicle & $6.9 \pm 0.3$ & $5.0 \pm 0.3$ & $P<0.0004$ \\
\hline Future largest subordinate follicle & $7.3 \pm 0.3$ & $5.4 \pm 0.3$ & $P<0.0003$ \\
\hline \multicolumn{4}{|l|}{ Maximum size of dominant follicle } \\
\hline Diameter (mm) & $15.5 \pm 1.0$ & $15.2 \pm 1.1$ & NS \\
\hline Number of days from emergence & $8.6 \pm 1.0$ & $10.2 \pm 1.1$ & NS \\
\hline \multicolumn{4}{|l|}{ Wave characteristics } \\
\hline Width of base (number of days) ${ }^{b}$ & $1.3 \pm 0.2$ & $2.6 \pm 0.6$ & $P<0.03$ \\
\hline \multicolumn{4}{|l|}{ Number of follicles } \\
\hline $4.0-4.9 \mathrm{~mm}$ & $1.7 \pm 0.6$ & $2.9 \pm 0.7$ & NS \\
\hline$\geqslant 5.0 \mathrm{~mm}$ & $5.0 \pm 1.0$ & $4.9 \pm 0.6$ & NS \\
\hline
\end{tabular}

a rbFSH treatment to simulate an FSH surge was carried out on days 3-5. Day 0 is the day on which the largest follicle of wave 1 reached $\geqslant 8.5 \mathrm{~mm}$ (expected beginning of follicle deviation).

${ }^{b}$ Number of days for emergence of all follicles $\geqslant 4.0 \mathrm{~mm}$ of wave 2 .

NS: not significant.

diameter or in the day on which $\mathrm{F} 1$ of wave 1 reached a maximum diameter (controls: day $6.3 \pm 0.6,16.5 \pm 0.7 \mathrm{~mm}$; treated: day $7.0 \pm 0.6,17.5 \pm 0.6 \mathrm{~mm}$ ) or in diameter profile of F2 (not shown).

The FSH surge in two of seven rbFSH-treated heifers was multi-modal. The first portion of the surge was included in the means and occurred on the days of the induced surge 2 in the other rbFSH-treated heifers. In one heifer with a bimodal surge, a separate wave with a dominant follicle emerged with each portion of the surge. In the second heifer, the emergence of follicles encompassed a base of 7 days with a dominant follicle emerging at the end of the first portion of the surge and another in association with the second portion (Fig. 4). The diameter of F1 temporally associated with the first portion of the surge reached only $5.7 \mathrm{~mm}$.

\section{Discussion}

The concentrations of FSH in the control heifers continued to decrease for 1.5 days after the day of the expected start of deviation of follicle diameter during wave 1 in agreement with studies by Ginther et al. (1999, 2000b). An apparent minor FSH surge occurred on average between day 1.5 and day 4.5 , as indicated by a significant increase in FSH concentration between day 1.5 and day 3.0, and a decrease that approached significance between day 3.0 and day 4.5.
A confirmatory study will be needed because of the unexpected occurrence and a probability for a decrease that only approached significance.

The increasing concentrations of oestradiol beginning approximately on the day of expected deviation in follicle diameter are in agreement with previous studies and have been attributed to the developing dominant follicle (Ginther et al., 2000a,b). The decrease in oestradiol that begins 2 days after the start of follicle deviation in wave 1 seems consistent with reports of decreases that start 4 days after oestrus (Badinga et al., 1992; Sunderland et al., 1996). Maximal oestradiol concentration occurred when the dominant follicle reached a mean of $12.5 \pm 0.7 \mathrm{~mm}$ in diameter. Thus, the decrease in oestradiol occurred during the later portion of the growth phase and early plateau phase of the dominant follicle of wave 1 and reached low concentrations before the peak of FSH surge 2 or the emergence of wave 2 on day 5 . The apparent temporal relationship between oestradiol and FSH involved low concentrations of oestradiol, implying considerable sensitivity of cattle to oestradiol. In this regard, a single injection of $0.02 \mathrm{mg}$ oestradiol resulted in a significant reduction in the $\mathrm{FSH}$ increase that followed ablation of F1 at the expected start of deviation of follicle diameter (Ginther et al., 2000a). The maximum circulating concentration that resulted from the $0.02 \mathrm{mg}$ injection was 3.6-fold higher than the assay sensitivity, which is close to the 3.2-fold difference in the present study. 


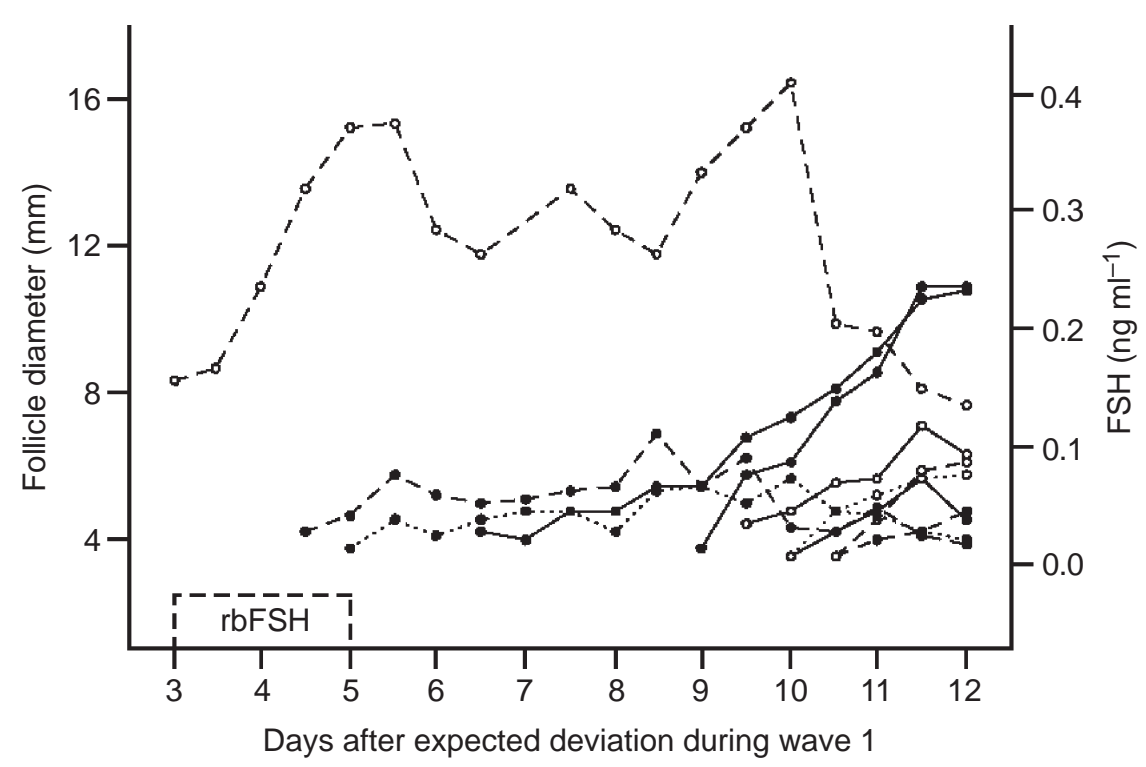

Fig. 4. FSH concentrations (--O--) and follicle diameters for individual follicles in a recombinant bovine (rb)FSH-treated heifer with a multi-modal FSH profile, probably representing rbFSH at first and endogenous FSH later. Follicles emerged throughout the prolonged surge.

The increase in oestradiol and the continuing decrease in FSH occurred approximately on the same days. The decrease in oestradiol was associated temporally with the increase in FSH. These temporal results are consistent with a reported conclusion of a functional reciprocal relationship between the two hormones (Ginther et al., 2000a). The indications that FSH concentrations were reduced by low circulating concentrations of oestradiol do not clarify the relative role of other follicular factors, especially inhibin (Bleach et al., 2001).

The recombinant DNA technology that was used to prepare the rbFSH has been described, and the biological activity of the rbFSH preparation was parallel to that of a 1988 USDA bFSH standard based on in vitro and in vivo bioassays (Chappel et al., 1988). The low immunological crossreactivity of the rbFSH preparation was unexpected and has not been reported in other studies in which the same rbFSH product was used. The reason for the low crossreactivity is unknown, but speculatively may reflect, at least in part, the use of highly purified bFSH assay standard in the present study compared with the standard used in characterizing the rbFSH product. In this regard, the antiovine FSH and the bovine FSH reference standard used in the present study have been validated for assay of bovine FSH in our laboratory (Adams et al., 1992). The mean dose of rbFSH that was used in the present study is similar to the doses of the same product used by others in studies in cattle for basic follicle research (Adams et al., 1993; Mihm et al., 1997; Rivera and Fortune, 2001). Furthermore, the total 2 day quantity for the five treatments at $12 \mathrm{~h}$ intervals $(9.5 \mathrm{mg})$ was close to the quantity that induced a positive but minimal superovulatory response (Looney et al., 1988;
Wilson et al., 1989). Unlike in previous studies, the rbFSH was given in progressively increasing and decreasing quantities with the expectation of simulating a wave-stimulating FSH surge. This goal was accomplished, as indicated by the non-significant differences between the control and rbFSHtreated groups in maximal FSH concentration during the surge and in concentrations for 5.5 days after the first apparent increase in the means.

The control heifers had two or three major follicular waves for an interovulatory interval, consistent with previous studies in several laboratories (Ginther et al., 1996). Although rbFSH treatment did not increase the mean number of major waves, two of seven rbFSH-treated heifers had four follicular waves. In contrast, none of 54 control heifers in this and previous studies (Ginther et al., 1989; Kulick et al., 2001) had four waves. An increase in the number of waves can be expected when the emergence of one of the waves is hastened, as shown by cauterization of the dominant follicle of wave 1 (Ko et al., 1991). Each major wave was associated with a prominent FSH surge, as reported by Adams et al. (1992).

A finding that has not been reported previously in cattle is the occurrence of minor waves in both control and rbFSH-treated heifers. Such waves occurred in $50 \%$ of heifers toward the end of the interovulatory interval. These waves did not represent the beginning of a major wave because the follicles regressed before the end of the interovulatory interval. Emergence of the minor waves seemed to be associated with an FSH surge in five of seven heifers; however, a significant change in FSH concentrations was not detected when concentrations were normalized to the day of wave emergence. Therefore, clarification 
of the relationship between minor waves and FSH increases requires further study. Minor waves with associated FSH surges have been reported in mares (Ginther and Bergfelt, 1992).

In two rbFSH-treated heifers with an apparent multimodal FSH surge 2, the first portion of the surge occurred on the days of the induced surge in the other treated heifers and apparently represented the injected rbFSH. The second portion apparently resulted from endogenous $\mathrm{FSH}$ but this could not be determined directly. Surge 2 , including the first portion of the multi-modal surge in the two heifers and the associated follicular wave 2, occurred an average of 2 days earlier in the treated group than in the controls. The characteristics of wave 2, including maximum diameter of the largest follicle, were similar between the two groups. However, an exception was that the base of the follicular wave lasted for about 1 more day in the rbFSH-treated group.

The early induction of a follicular wave when rbFSH was administered during the low FSH concentrations between surges 1 and 2 supported the hypothesis that the hiatus in emergence of follicles between waves in the control heifers was attributable to the low FSH concentrations. This result did not provide support for the presence of a direct follicle suppressor in delaying the emergence of wave 2. It is not known why rbFSH did not hasten the emergence of wave 2 in the study by Adams et al. (1993), in which $2 \mathrm{mg}$ per injection of the same product was administered at $12 \mathrm{~h}$ intervals for 2 days (total quantity, $10 \mathrm{mg}$ ). Progressively increasing and decreasing doses were not used to simulate an FSH surge, as in the present study. Several reservations must accompany the interpretation that the results of the present study are not consistent with the presence of a direct follicle-to-follicle suppressor. First, a potential suppressor may be released only when FSH concentrations are low, and its release could have been prevented or overridden by the exogenous FSH. Second, a suppressor may have been present soon after deviation in follicle diameter or before the start of FSH treatment. Third, in the present study a wave with a dominant follicle did not develop in one of the treated heifers during the first portion of a multi-modal surge; the first portion is likely to represent rbFSH. The largest follicle that emerged during the first portion of the multi-modal profile reached $5.7 \mathrm{~mm}$, which may have been inadequate to stimulate a return of FSH to baseline (Ginther et al., 2001a). The inhibition of follicle growth during the early or induced portion of the surge could have resulted from the presence of a follicle suppressor in this heifer. Although this occurred in only one of seven heifers, it encourages caution in the overall interpretation.

In conclusion, during the interval between FSH surges 1 and 2 in the control heifers, concentrations of FSH decreased or increased as oestradiol increased or decreased, respectively, in a reciprocal relationship. Treatment of heifers with rbFSH 3-5 days after expected deviation of follicle diameter in wave 1 resulted in a peak in surge 2 and the emergence of wave 2 that was 2 days earlier than in control heifers. The results from the present study indicate that the hiatus in follicle growth between waves is attributable to low FSH concentrations.

The authors thank Pharmacia for a gift of lutalyse, the USDA Animal Health Program and A. F. Parlow of the National Hormone and Pituitary Program for gonadotrophin-assay reagents, and J. Haughian and S. Jensen for technical assistance.

\section{References}

Adams GP, Matteri RL, Kastelic JP, Ko JCH and Ginther OJ (1992) Association between surges of follicle stimulating hormone and the emergence of follicular waves in heifers Journal of Reproduction and Fertility 94 177-188

Adams GP, Kot K, Smith CA and Ginther OJ (1993) Selection of a dominant follicle and suppression of follicular growth in heifers Animal Reproduction Science 30 259-271

Armstrong DG and Webb R (1997) Ovarian follicular dominance: the role of intraovarian growth factors and novel proteins Reviews of Reproduction 2 139-146

Badinga L, Driancourt MA, Savio JD, Wolfenson D, Drost M, de la Sota RL and Thatcher WW (1992) Endocrine and ovarian responses associated with the first-wave dominant follicle in cattle Biology of Reproduction 47 871-883

Bleach ECL, Glencross RG, Feist SA, Groome NP and Knight PG (2001) Plasma inhibin A in heifers: relationship with follicle dynamics, gonadotropins and steroids during the estrous cycle and after treatment with bovine follicular fluid Biology of Reproduction 54 743-752

Bodensteiner KJ, Kot K, Wiltbank MC and Ginther OJ (1996) Synchronization of emergence of follicular waves in cattle Theriogenology $\mathbf{4 5}$ 1115-1128

Chappel RA, Looney C and Bondioli K (1988) Bovine FSH produced by recombinant DNA technology Theriogenology 29235 (Abstract)

Evans ACO, Komar CM, Wandji S-A and Fortune JE (1997) Changes in androgen secretion and luteinizing hormone pulse amplitude are associated with the recruitment and growth of ovarian follicles during the luteal phase of the bovine estrous cycle Biology of Reproduction $\mathbf{5 7}$ 394-401

Ginther OJ and Bergfelt DR (1992) Associations between FSH concentrations and major and minor follicular waves in pregnant mares Theriogenology 38 807-821

Ginther OJ, Knopf L and Kastelic JP (1989) Temporal associations among ovarian events in cattle during oestrous cycles with two and three follicular waves Journal of Reproduction and Fertility 87 223-230

Ginther OJ, Wiltbank MC, Fricke PM, Gibbons JR and Kot K (1996) Selection of the dominant follicle in cattle Biology of Reproduction $\mathbf{5 5}$ 1187-1194

Ginther OJ, Bergfelt DR, Kulick LJ and Kot K (1999) Selection of the dominant follicle in cattle: establishment of follicle deviation in less than 8 hours through depression of FSH concentrations Theriogenology 52 1079-1093

Ginther OJ, Bergfelt DR, Kulick LJ and Kot K (2000a) Selection of the dominant follicle in cattle: role of estradiol Biology of Reproduction $\mathbf{6 3}$ 383-389

Ginther OJ, Bergfelt DR, Kulick LJ and Kot K (2000b) Selection of the dominant follicle in cattle: role of two-way functional coupling between follicle-stimulating hormone and the follicles Biology of Reproduction 62 920-927

Ginther OJ, Beg MA, Bergfelt DR, Donadeu FX and Kot K (2001a) Follicle selection in monovular species Biology of Reproduction 65 638-647

Ginther OJ, Bergfelt DR, Beg MA and Kot K (2001b) Effect of LH on circulating oestradiol and follicular-fluid factors during follicle deviation in cattle Reproduction 122 103-110

Ko JCH, Kastelic JP, Del Campo MR and Ginther OJ (1991) Effects of a dominant follicle on ovarian follicular dynamics during the oestrous cycle in heifers Journal of Reproduction and Fertility 91 511-519

Kulick LJ, Kot K, Wiltbank MC and Ginther OJ (1999) Follicular and 
hormonal dynamics during the first follicular wave in heifers Theriogenology 52 913-921

Kulick LJ, Bergfelt DR, Kot K and Ginther OJ (2001) Follicle selection in cattle: follicle deviation and codominance within sequential waves Biology of Reproduction 65 839-846

Law AS, Baxter G, Logue DN, O'Shea T and Webb R (1992) Evidence for the action of a bovine follicular fluid factor(s) other than inhibin in suppressing follicular development and delaying oestrus in heifers Journal of Reproduction and Fertility 96 603-616

Looney CR, Bondioli KR, Hill KG and Massey JM (1988) Superovulation of donor cows with bovine follicle-stimulation hormone $(\mathrm{bFSH})$ produced by recombinant DNA technology Theriogenology 29271 (Abstract)

Mihm M, Good TEM, Ireland JLH, Ireland JJ, Knight PG and Roche JF (1997) Decline in serum follicle-stimulating hormone concentrations alters key intrafollicular growth factors involved in selection of the dominant follicle in heifers Biology of Reproduction 57 1328-1337

Rivera GM and Fortune JE (2001) Development of codominant follicles in cattle is associated with follicle-stimulating hormone-dependent insulinlike growth factor binding protein-4 protease Biology of Reproduction 65 112-118

Sunderland SJ, Knight PG, Boland MP, Roche JF and Ireland JJ (1996)
Alterations in intrafollicular levels of different molecular mass forms of inhibin during development of follicular- and luteal-phase dominant follicles in heifers Biology of Reproduction 54 453-462

Turzillo AM and Fortune JE (1990) Suppression of the secondary FSH surge with bovine follicular fluid is associated with delayed ovarian follicular development in heifers Journal of Reproduction and Fertility $\mathbf{8 9}$ 643-653

Wilson JM, Moore K, Jones AL and Looney CR (1989) Recombinant bovine follicle stimulating hormone: dose and duration regimens for superovulation of embryo donors Theriogenology 31273 (Abstract)

Wood SC, Glencross RG, Bleach EC, Lovell R, Beard AJ and Knight PG (1993) The ability of steroid-free bovine follicular fluid to suppress FSH secretion and delay ovulation persists in heifers actively immunized against inhibin Journal of Endocrinology 136 137-148

Received 5 April 2002.

First decision 13 June 2002.

Revised manuscript received 20 June 2002.

Accepted 26 June 2002. 